Revista Signos

2008, 41(67)

$119-126$

\section{Palabra y término: ¿Diferenciación o complementación?}

Discurso de incorporación a la Academia Chilena de la Lengua,
como Miembro Correspondiente por Valparaíso

Valparaíso, 20 de octubre, 2006

Pontificia Universidad Católica de Valparaíso

Chile

\title{
Agradecimientos
}

Señor Alfredo Matus Olivier, Director de la Academia Chilena de la Lengua, Señor Claudio Elórtegui, Rector Subrogante de la Pontificia Universidad Católica de Valparaíso, Señor Jorge Sapunar, Vice Gran Canciller de nuestra Universidad, Decanos de las diferentes Facultades de nuestra Universidad, Miembros de la Academia Chilena de la Lengua presentes, colegas, alumnos y alumnas, señores y señoras:

Mi agradecimiento por este alto honor, a Don Alfredo Matus Olivier, en nombre de la Academia Chilena de la Lengua, por la confianza depositada a la que solo puedo corresponder con mi dedicación y mi trabajo a las tareas que la Academia realiza.

Y, en este momento dedicado a los agradecimientos, no puedo dejar de mencionar especialmente a la Académica de Número de nuestra Academia que tuvo a bien presentar mi candidatura: mi queridísima maestra, colega y amiga: Marianne Peronard. Valga también mi reconocimiento a Andrés Gallardo, académico que hoy ha accedido en forma entusiasta y generosa a presentarme ante ustedes. No quiero terminar esta parte de mi discurso sin recordar a las personas que de un modo más directo han influido en mi vida dedicada a la docencia y a la investigación en esta querida Pontificia Universidad Católica de Valparaíso que me ha cobijado y de la que también soy ex alumna. En primer lugar, a mis padres, pues ellos me dieron todas las facilidades para que pudiese desarrollar mis capacidades desde mi lejana Punta Arenas, mi ciudad natal, y desde donde llegué para anclarme en este bello puerto al que nunca imaginé representar. A mi familia que tengo la suerte de tenerla hoy conmigo y de la que siempre he sentido su apoyo incondicional. A un gran maestro, hoy fallecido, Académico de la Lengua también, Don Luis Gómez Macker, a mis colegas, con quienes comparto no solo el amor por la Lingüística, sino también su entusiasmo y dedicación 
a la enseñanza y la investigación. A todos los colaboradores que he tenido a lo largo de mi vida académica. Sin la ayuda y apoyo constantes de todos ustedes, no estaría yo hoy aquí en este acto.

Ciertamente, el estar hoy aquí supone para mí un gran privilegio que nunca había soñado alcanzar. Gracias nuevamente a todos ustedes por estar hoy aquí, en un momento irrepetible y emocionante para mí.

Paso ahora al tema de mi discurso que he denominado: "Palabra y término: ¿Diferenciación o complementación?" La verdad es que me costó mucho decidirme por el tema, mi deseo era que fuera simple, pero a la vez esclarecedor, y me decidí por desentrañar dos palabras en apariencia modestas, pero que encierran una cantidad de sentidos trascendentes para quienes nos preocupamos por el lenguaje. Y tal como decía Mario Benedetti en el Olvido está lleno de memoria: "Cómo puedes manejar las palabras, desactivarlas, solazarte en ellas, cómo puedes dejar que las palabras se evadan de tu corazón empecinado".

La 'palabra', que inicialmente nos llegó como parabla, al igual que parábola, provienen del latín parabola (comparación, símil), que a su vez se deriva del griego parabolé (comparación, alegoría). El sustantivo griego se formó a partir del verbo parabállein, que significaba "poner al lado, comparar", una idea que históricamente está presente tanto en palabra como en parábola. Parábola y palabra, ambas nacidas de un mismo seno materno, evolucionaron en forma paralela; palabra fue paravla y parávoa, además de la forma mencionada al comienzo, y, en los poemas de Berceo, todavía aparece con el sentido de "comparación"; más tarde significó "frase" y luego "vocablo".

Definir qué se entiende por palabra no es fácil. Existen distintos criterios o enfoques:

- fonológico: Segmento limitado por junturas o pausas;

- formal: Mínima forma libre, caracterizada por la posibilidad de aparecer libremente en cualquier posición de la cadena hablada;

- funcional: Unidad dotada de una función, aunque hay unidades mayores y menores que la palabra;

- semántico: Asociación de un sentido dado y un conjunto de sonidos dado dentro de una función gramatical;

- comunicativo: Elemento articulador y fundamental de la comunicación humana.

En cuanto a 'término', del latín terminus, deslinde, límite; de ahí que cualquier símbolo que pueda ser un constituyente directo de una proposición se le llama término, como lo entendía el gran pensador romano Boecio. De ordinario, los lógicos dicen que una proposición categórica tie- 
ne "dos términos", su sujeto y su predicado. La designación correcta del sujeto y el predicado, según su doctrina, es los extremos, que se traduce de la misma palabra griega que término. En palabras de Sager (2000), término puede entenderse como:

- designación de una unidad cognitiva, ya que un término se refiere a un concepto dentro de una estructura de conocimiento;

- simplemente una palabra o una frase que denota un individuo o una clase o el componente proposicional que expresa;

- expresión normalizada, prescrita en su uso por un grupo de usuarios para la comunicación dentro de este grupo; un término designa las entidades, actividades, cualidades y relaciones que el grupo ha normalizado. En este sentido, el término forma parte de un lenguaje artificial creado por el organismo normalizador, porque solamente tiene el significado del concepto definido como parte del léxico de ese lenguaje;

- signo lingüístico, en forma de sustantivo, o signo extralingüístico que pertenece a un lenguaje o un código artificial. Como signo extralingüístico, un término se puede expresar por números, letras u otros símbolos. En el discurso escrito se trata a estos signos como sustantivo; en el habla estos signos devienen en unidades fonológicas.

Este primer recorrido nos lleva a determinar ciertos rasgos diferenciadores entre la 'palabra' y el 'término', sobre todo en la acepción de término como expresión de un lenguaje especializado, lo que ha permitido hoy que la palabra o el léxico, por un lado, y el término, por otro, conformen distintas disciplinas, como la lexicología y lexicografía para los primeros, que se ocuparán del marco teórico y del proceso de construcción de diccionarios de lengua general, respectivamente, y la terminología y la terminografía, que se ocuparán de la construcción de un marco teórico sobre los términos y de la aplicación de dicho marco a la elaboración de diccionarios especializados u otros productos terminográficos.

El término, en este contexto, es el nombre o designación de un concepto en un campo temático particular. Puede tratarse de una palabra del lenguaje general que adopta un sentido especializado, una palabra creada con un sentido especializado, un sintagma o grupo de palabras con un sentido único y especializado, un símbolo, una fórmula química o matemática, un nombre científico en latín o en griego, un acrónimo, una sigla, la denominación o título oficial de un cargo, organismo o entidad administrativa.

Por otra parte, un término o unidad terminológica en un lenguaje de especialidad se distingue de una palabra en la lengua general por lo siguiente:

- su relación unívoca (fenómeno denominado monosemia) con el concepto especializado que designa en un campo del saber específico; 
- la estabilidad de la relación entre la forma léxica con que se designa a un concepto y el contenido semántico que ella porta (fenómeno denominado lexicalización);

- la frecuencia de su uso y su entorno contextual (co-ocurrencia) relativamente fijo (lo que se conoce como fraseología);

- los indicadores tipográficos (cursiva, negrita, comillas, etc.) con que se marcan en un texto;

- la existencia de un conjunto más bien limitado de estructuras morfológicas y léxicas: por lo general suelen ser sustantivos (simples, derivados o compuestos), como, por ejemplo, "telecomunicaciones", aunque en ocasiones los términos también pueden ser verbos, "telecopiar", adjetivos o sintagmas nominales, "Organización Internacional del Trabajo", verbales o adjetivales.

Sin embargo, para Cabré (1999), entre los términos y las llamadas palabras del léxico de las lenguas se dan más coincidencias que divergencias. Y esta constatación la lleva a la propuesta de explicar términos y palabras desde una misma teoría de las unidades léxicas, sin negar la especificidad de los términos, básicamente en los aspectos relativos a su semántica y su uso.

A nuestro entender, siguiendo a Langacker (1987), tanto la lexicología como la terminología responden a una misma necesidad, la de sistematizar una estructuración léxica que no es más que una estructura conceptual formalizada con fines simbólicos, según las convenciones lingüísticas. Es, por tanto, en la rama aplicada donde la teoría se adecua a los distintos marcos contextuales y situaciones comunicativas, y donde se subraya la diferencia entre el tratamiento de una u otra, así como la presentación en bancos de datos, glosarios, etc. Dicho de otra forma, el uso por parte de los hablantes de unos elementos léxicos específicos y no otros, y su recopilación, según criterios léxico-terminográficos, es precisamente lo que determina la distinción entre las disciplinas.

Y, más aún, una diferenciación entre 'palabra' y 'término' tendría repercusiones en la dicotomía que Pérez Hernández (2002) plantea entre lengua general y lenguaje de especialidad, que parece lógica si volvemos a los fundamentos de la teoría terminológica tradicional. En efecto, en el seno de esta teoría, los términos se consideran como unidades específicas de un ámbito de especialidad y su uso queda circunscrito a ese ámbito; por tanto, solo es de interés para la terminología la comunicación entre especialistas. No obstante, frente a este planteamiento, tal como ya lo mencionábamos anteriormente, Cabré (1999: 132) mantiene su postura de la irrealidad de dicha separación:

"el conocimiento especializado no puede guardarse en compartimentos estancos, cada uno con su terminología propia ya que el saber es un continuo y su segmentación en materias es puramente metodológica, que en ningún momento responde a una segmentación en el conocimiento. La demarcación de diferencias especiales que definen los lenguajes de especialidad frente a la lengua general es una cuestión todavía hoy bastante polémica y difusa". 
Este planteamiento, sin embargo, no es nuevo, ya que Rosch (1978) afirmaba que, por lo general, los términos pertenecen típicamente a planos de especificidad superordinados y subordinados al nivel básico de categorización. La noción de concepto superordinado y subordinado, con respecto al nivel básico de categorización que caracteriza los términos especializados, es consustancial a su naturaleza. Por ejemplo, en el caso del cuerpo humano, "mano", "cabeza", "corazón", corresponderían al nivel básico de categorización; "glándula", "enzima", "sistema endocrino", al nivel superordinado; y "leucocito", "alvéolo", "falange", al nivel subordinado.

Se trata, por tanto, de un gradiente, de un continuo de especificidad que no permite establecer líneas divisorias claras por encima o por debajo del nivel básico de categorización. Hay unidades léxicas como "gen", "miembro" o "adrenalina" que no pueden ser claramente desterradas del nivel básico de categorización, pero son al mismo tiempo términos específicos propios de los lenguajes especializados (Márquez Linares \& García de Quesada, 2003). Según este nivel de categorización, los términos se ubicarán en el nivel subordinado, mientras que las palabras pertenecerán al nivel básico de categorización. De ahí que se haya optado por la denominación 'unidad léxica', ya que permite evitar las connotaciones asociadas a 'palabra' y 'término'.

A pesar de esta naturaleza polémica, que impide trazar una línea divisoria clara entre lenguajes de especialidad y lengua general, sin lugar a dudas, la lengua está constituida por un conjunto diverso de subcódigos que los hablantes usan, seleccionándolos según las necesidades expresivas y las características particulares del contexto comunicativo en que se encuentran. Tanto en el marco de una conversación cotidiana, como en una sesión clínica, por citar dos ejemplos prototípicos de un discurso general y otro especializado, respectivamente, se seleccionan cada uno de los elementos que integran el proceso de comunicación: desde la terminología y el registro hasta la forma de gesticular o la entonación. Si bien es difícil la tipificación, la definición de un tipo de lenguaje u otro, lo que es cierto es que los participantes saben de qué elementos hacer uso para comunicarse de forma exitosa.

El 'lenguaje de especialidad' se entiende, entonces, como un subconjunto, definido por factores pragmáticos, de la lengua global que abarcaría tanto a la lengua general como a todos los posibles sublenguajes. En otras palabras, se trata de: a) conjuntos "especializados", ya sea por la temática, la experiencia, el ámbito de uso o los usuarios; b) se presentan como un conjunto con características interrelacionadas, no como fenómenos aislados; y c) mantienen la función comunicativa como predominante, por encima de otras funciones complementarias (Cabré, 1993).

Para muchos, es esta idea, según Sager (1990), la que justificaría el establecimiento de una diferencia entre los términos que tienen una referencia concreta con respecto a una disciplina determinada y las palabras que tienen, por el contrario, una referencia general con respecto a una gran variedad de disciplinas. La única diferencia entre estos dos conceptos está en función del contexto en el que se actualice una unidad léxica determinada. 
En cuanto a las características comunes que presentan, los lenguajes especializados pueden aglutinarse en torno a su tendencia restrictiva que es la que los sitúa como tipos mixtos a medio camino entre los lenguajes artificiales y las lenguas naturales (Cabré, 1993). Es restrictiva en cuanto a los siguientes aspectos:

- su adquisición, que debe hacerse de forma consciente;

- su flexibilidad, que se ve constreñida por la incorporación de lenguajes artificiales que hacen referencia a conceptos y funciones únicos del dominio;

- su manifestación suele ser el medio escrito y por lo tanto más controlado;

- las funciones, que suelen estar reducidas a lo estrictamente descriptivo, clasificatorio y comunicativo; y

- la intención informativa o directiva.

Si tomamos el trabajo de García de Quesada (2001), podemos inferir que los temas en el campo de oncología clínica, por ejemplo, son ajenos al público general y, por tanto, exigen un aprendizaje tanto del sistema conceptual como de la terminología que los designa. De este modo, el lenguaje en este ámbito variará según los usuarios y las funciones en las cuales operará, ya que los especialistas lo utilizarán tanto para comunicarse con sus pares, como también con sus pacientes.

Tal como mencionamos con anterioridad, los lenguajes especializados pueden variar dependiendo de determinados factores pragmáticos y sociolingüísticos; es decir, dependiendo de factores de uso que son los que los definen. Para la descripción de esta variación, Cabré (1997) propone utilizar un eje horizontal y otro vertical.

La variación horizontal se refiere a la temática y la perspectiva. Dado que la temática especializada es una característica definitoria de estos lenguajes, en función de esta se puede establecer una primera clasificación de los mismos. Pero además de la temática habrá que tener en cuenta la perspectiva desde la que se aborda el mensaje, en el sentido que el conocimiento científico puede ser tratado de forma trivial, sin atenerse a las estructuras conceptuales del dominio y, por tanto, como conocimiento general (Cabré, 1998).

La variación vertical incluye la intención y el nivel de especialización, que fundamentalmente vienen determinados por el emisor. Este será un especialista que está motivado a transmitir un mensaje lingüístico sobre un asunto determinado y que espera que el receptor lo reciba en una situación determinada, es decir, marcada. Si partimos de la base de que el emisor quiere de alguna manera modificar el conocimiento del receptor, habrá de tener en cuenta, en primer lugar, las características de este. Una vez identificada la audiencia, la intención habrá de manifestarse en el mensaje de forma que los receptores puedan acceder al contenido (Sager, 1990). 
En este sentido, es imprescindible distinguir entre el 'discurso especializado' (con distintos grados de especialización), dirigido a los especialistas; el 'discurso didáctico', destinado al personal en formación; y el 'discurso divulgativo', enfocado hacia el público general. Estos niveles de competencia en las producciones lingüísticas se reflejarán en el mayor o menor uso de terminologías específicas (Condamines, 1993). De este modo, la comunicación especializada requiere que la terminología se adapte a cada género discursivo que viene determinado por la cantidad de información compartida entre emisor y receptor y la finalidad del texto.

Podemos concluir afirmando que si bien los lenguajes especializados adoptan ciertas propiedades de los lenguajes artificiales, también poseen rasgos pertenecientes a la lengua general. Por tanto, la línea divisoria entre la lengua general y la especializada habrá que buscarla en función de criterios pragmáticos derivados del uso, así como en función de los niveles de categorización existentes en la mente del hablante. De esta manera, las construcciones lingüísticas de todo lenguaje especializado pertenecen a la lengua en su conjunto, ya que las unidades léxicas -tanto palabras como términos- son parte del sistema y han de satisfacer las reglas gramaticales generales (Harris 1982).

Aún más, como lo expresa Pérez Hernández (2002: 128):

"las características comunes que los lenguajes de especialidad comparten con la lengua general y el constante transvase de unidades de una a otras (...) son la causa fundamental de la dificultad que existe para separar las palabras (como unidades léxicas de la lengua general) de los términos (unidades de los lenguajes de especialidad)".

En definitiva, no olvidemos que los términos están formados por palabras, cuyo poder mediador en el proceso de construcción de sentido del mundo natural, social y cultural es indiscutible, posibilitando así la comunicación entre los hombres.

\section{REFERENCIAS BIBLIOGRÁFICAS}

Cabré, M. (1993). La terminología. Teoría, métodos, aplicaciones. Barcelona: Antártida.

Cabré, M. (1997). Taula de formants cultes. Barcelona: Universitat Pompeu Fabra.

Cabré, M. (1998). Introducción a la teoría general de la terminología y a la lexicografía terminológica. Barcelona: Wüster.

Cabré, M. (1999). La terminología. Representación y comunicación. Una teoría de base comunicativa y otros artículos. Barcelona: Universitat Pompeu Fabra.

Condamines, A. (1993). Un exemple d'utilisation de connaisances de sémantique lexicale. Cahiers de Lexicologie, 1, 25-65. 
García de Quesada, M. (2001). Estructura definicional terminográfica en el subdominio de la oncología clínica [en línea]. Disponible en: http: / /elies.rediris.es/elies14/

Harris, Z. (1982). Discourse and sublanguage. En R. Kittredge \& J. Lehrberger (Eds.), Sublanguages: Studies on language in restricted semantic domains (pp. 231-236). Berlín: W. de Gruyter.

Langacker, R. (1987). Foundations of cognitive grammar. Vol. I. Theoretical prerequisites. Stanford: Stanford University Press.

Márquez Linares, C. \& García de Quesada, M. (2003). Análisis definicional terminográfico en la base de conocimiento Ontoterm ${ }^{\circledR}$. En M. Correia (Ed.), Terminología e industrias de la lengua (pp. 669-684). Barcelona: ILTEC.

Pérez Hernández, Ch. (2002). Explotación de los corpora textuales informatizados para la creación de bases de datos terminológicas basadas en el conocimiento [en línea]. Disponible en: http://elies.rediris.es/elies18/

Rosch, E. (1978). Principles of categorization. En E. Rosch \& B. Lloyd (Eds), Cognition and categorization (pp. 27-48). Hillsdale, N.J.: Erlbaum.

Sager, J. (1990). A practical course in terminology processing. Amsterdam: Benjamins.

Sager, J. (2000). Essays on definition. Amsterdam: Benjamins. 